\title{
Change in von Willebrand factor and carotid intima-media thickness in hypothyroid patients with normal thyroid function after levothyroxine replacement therapy
}

Toshiki Nagasaki, Masaaki Inaba, Yasuko Henmi, Yasuro Kumeda, Misako Ueda, Hideki Tahara, Eiji Ishimura, Naoyoshi Onoda ${ }^{1}$, Tetsuro Ishikawa ${ }^{1}$ and Yoshiki Nishizawa

Department of Metabolism, Endocrinology and Molecular Medicine and ${ }^{1}$ First Department of Surgery, Osaka City University Graduate School of Medicine, 1-4-3, Asahi-machi, Abeno-ku, Osaka 545-8585, Japan

(Correspondence should be addressed to M Inaba; Email: inaba-m@med.osaka-cu.ac.jp)

\begin{abstract}
Objective: This study examined whether levothyroxine $\left(\mathrm{L}-\mathrm{T}_{4}\right)$ replacement might affect serum markers of endothelium injury, including von Willebrand factor (vWF), factor VIII activity and thrombomodulin (TM), during normalization of increased intima-media thickness (IMT) in the common carotid artery (CCA) in hypothyroid patients after $\mathrm{L}_{-} \mathrm{T}_{4}$ replacement therapy.

Patients and methods: Thirty-three hypothyroid patients were examined for vWF, factor VIII, TM and CCA IMT before and after 1 year of normalization of thyroid function by $\mathrm{L}_{-} \mathrm{T}_{4}$ replacement. CCA IMT was measured from digitized still images taken during scanning by high-resolution ultrasonography as an indicator of early atherosclerosis.

Results: Serum factor VIII and vWF increased significantly during 1 year of normalization of thyroid function (from $122.7 \pm 9.4$ to $151.3 \pm 18.8 \%(P<0.05)$ and from $109.9 \pm 9.6$ to $135.2 \pm 12.4 \%$ $(P<0.005)$ respectively), although these values all fell within the respective normal range. Serum $\mathrm{TM}$, in contrast, did not change appreciably in response to $\mathrm{L}_{-} \mathrm{T}_{4}$ treatment, moving from $2.57 \pm 0.15$ to $2.74 \pm 0.18 \mathrm{ng} / \mathrm{ml}(P=0.086)$. During 1 year of a euthyroid state, all patients showed a significant decrease in CCA IMT $(P<0.0001)$. Change in serum vWF, but not in factor VIII or TM, showed a positive correlation with that of CCA IMT during L- $\mathrm{T}_{4}$ replacement therapy. Furthermore, the change in serum vWF was significantly and independently associated with change in CCA IMT $(r=0.490, P=0.0038)$.

Conclusions: The present study demonstrated that the improvement of CCA IMT during L- $\mathrm{T}_{4}$ treatment might have the potential to attenuate an elevation of vWF and to attenuate vascular injury by the cardiovascular effects of thyroid hormone in hypothyroid patients.
\end{abstract}

European Journal of Endocrinology 150 125-131

\section{Introduction}

Serum levels of vascular injury markers, such as von Willebrand factor (vWF), factor VIII activity and thrombomodulin (TM), are known to increase in the hyperthyroid state $(1-3)$. Cardiovascular effects of thyroid hormone, characterized by an increase in cardiac output with a widened pulse pressure, should affect hemodynamic changes in general vessels (4-6) and induce endothelial injury (7). In contrast, these endothelial injury markers are reported to be within normal limits in hypothyroid patients $(8,9)$, and thus it is yet to be determined with certainty whether endothelial injury occurs in hypothyroidism.

Hypothyroidism, even in the latent form, is associated with increased morbidity from cardiovascular disease (10-13) and also with increases in arterial compliance and wall thickness in the radial artery (14). However, since there are few data on common carotid artery intima-media thickness (CCA IMT) in hypothyroidism and CCA IMT but not radial IMT is a significant predictor of cardiovascular events, it is important to know the changes in CCA IMT during the treatment of hypothyroidism and to elucidate factors affecting CCA IMT change. We recently reported that increased CCA IMT in hypothyroid patients is normalized by sustained normalization of thyroid function (15). A decrease in CCA IMT is associated with a reduction in the number of coronary events (16-18), establishing CCA IMT as a valuable indicator of atherosclerosis and thus a good predictor of cardiovascular events $(17-21)$.

This background scenario prompted us to examine whether (i) serum levels of vascular injury markers in 
hypothyroid patients might change after normalization of thyroid function by levothyroxine $\left(\mathrm{L}_{-} \mathrm{T}_{4}\right)$ replacement therapy, and (ii) which is the most important factor among clinical variables including blood pressure, body weight, thyroid hormone and CCA IMT to affect serum levels of these markers in hypothyroid patients during $\mathrm{L}_{-} \mathrm{T}_{4}$ replacement therapy.

\section{Patients and methods}

\section{Patients and study design}

The study was designed as an open prospective study. Written informed consent was obtained from each patient, and the study was approved by the ethical committee of Osaka City University Hospital. A group of hypothyroid patients (male/female, 5/28) were selected consecutively and studied during the 20-month period. The diagnosis of hypothyroidism was established on the basis of suppression of serum free thyroxine $\left(\mathrm{FT}_{4}\right)$ and free triiodothyronine $\left(\mathrm{FT}_{3}\right)$ to below the normal lower limit and elevation of serum thyroid-stimulating hormone (TSH) to above the normal upper limit. $\mathrm{L}_{-} \mathrm{T}_{4}$ therapy was adapted individually to maintain serum $\mathrm{FT}_{4}, \quad \mathrm{FT}_{3}$ and $\mathrm{TSH}$ values within the respective normal ranges. All patients had measurement of biochemical markers including serum vascular injury markers and CCA IMT before and after at least a year (12-14 months) of normalization of thyroid function. To avoid confounding by other factors known to affect arteriosclerosis, we excluded from the study: (i) patients taking medication known to affect CCA IMT, such as anti-hypertensive agents (22), lipid-lowering drugs (23), anti-platelet drugs (24) and bisphosphonates, including etidronate (25); and (ii) patients receiving other hormone replacement therapy (26).

\section{Serum parameters}

Blood was drawn just before ultrasonographical study after an overnight fast. As serum markers of endothelial injury, serum levels of coagulation factor VIII, vWF and TM were determined as described previously (1). Coagulation factor VIII was measured using a chromogenic substrate method for photometric determination of prothrombin time as previously described (27). vWF was measured as described previously $(28,29)$. Serum TM was determined by a one-step sandwich enzyme immunoassay, the reported sensitivity of which is $1 \mu \mathrm{g} / \mathrm{l}$ for soluble TM $(30,31)$. Total cholesterol, triglyceride and high-density lipoprotein (HDL)cholesterol were determined using an autoanalyzer. Low-density lipoprotein (LDL)-cholesterol was calculated according to the formula of Friedewald et al.(32). $\mathrm{FT}_{4}, \mathrm{FT}_{3}$ and $\mathrm{TSH}$ were measured using commercially available kits (Ortho-Clinical Diagnostics, Amersham, Bucks, UK) (33).

\section{Measurement of CCA IMT}

CCA IMT was determined in the supine position by high-resolution ultrasonography with a $10 \mathrm{MHz}$ inline sectascanner (SSD 610 CL; Aloka Co., Tokyo, Japan), as previously described $(20,21,34-36)$. To avoid inter-observer variation, CCA IMT was determined by the same experienced physician $(\mathrm{T} \mathrm{N})$, who was unaware of subject characteristics. Briefly, the CCA was scanned at the level of the bifurcation in both sides. Then the right side was used as representative because the coefficient of variation was significantly lower than in the left side (right vs left side: 3.4 vs $4.2 \%$ ). Using digitized still images of the arteries taken during scanning, IMT was measured in the far wall of the right CCA at sites of the most advanced atherosclerotic lesions, identified as diffuse and continuous projections with the greatest distance between the lumen-intimal interface and the media-adventitial interface but without atherosclerotic plaque, which was defined as localized lesions of thickness $\geq 2.0 \mathrm{~mm}$ $(35,36)$. These interfaces were manually traced and the mean value calculated as the mean of at least three still images obtained from the same section of the CCA. Furthermore, to avoid possible variation during 20 months, analyses of the two photos of CCA IMT in all patients before and after $\mathrm{L}_{-} \mathrm{T}_{4}$ treatment were performed on the same day.

\section{Statistical analysis}

Data are expressed as means \pm s.E. unless otherwise indicated. Statistical analysis was performed with the Stat View V system (Abacus Concepts, Berkeley, CA, USA) for the Macintosh computer. The difference in each parameter between before and after treatment was compared using the two-tailed Student's $t$-test for paired data. Independent association between one dependent and more than two independent variables was assessed by multiple regression analysis. Correlation of each vascular injury marker with other variables was assessed by simple regression analyses. $P$ values of less than 0.05 were considered statistically significant.

\section{Results}

Basal levels of serum vascular injury markers in the hypothyroid state before $L_{-} T_{4}$ treatment

Clinical characteristics of hypothyroid patients are shown in Table 1 . In the hypothyroid state, mean values of serum vWF, factor VIII and TM in hypothyroid patients were within the respective normal ranges determined by manufacturers (normal range: vWF: 6-170\%, factor VIII: 50-155\%, TM: $1.8-4.1 \mathrm{ng} / \mathrm{ml}$ ) (Table 1) (1). No correlation was found between the baseline value of each vascular injury marker and 
Table 1 Clinical variables in hypothyroid patients before and after 1 year of normalization of thyroid function by L-T replacement. Data are expressed as means \pm s.E. Difference of mean values between two groups is assessed by two-tailed Student's $t$-test for paired data.

\begin{tabular}{|c|c|c|c|}
\hline & Before treatment & After 1 year of euthyroid state & $\boldsymbol{P}$ \\
\hline Number of subjects & 33 & 33 & - \\
\hline Gender (female/male) & $28 / 5$ & $28 / 5$ & - \\
\hline Age (years) & $52.1 \pm 2.2$ & - & - \\
\hline Body weight (kg) & $55.9 \pm 1.4$ & $53.5 \pm 1.8$ & 0.007 \\
\hline BMI $\left(\mathrm{kg} / \mathrm{m}^{2}\right)$ & $22.9 \pm 0.5$ & $21.9 \pm 0.6$ & 0.005 \\
\hline Systolic BP (mmHg) & $117.1 \pm 2.2$ & $111.6 \pm 2.8$ & ns \\
\hline Diastolic BP (mmHg) & $72.8 \pm 1.5$ & $68.7 \pm 1.7$ & ns \\
\hline Pulse rate (per min) & $69.7 \pm 1.4$ & $72.8 \pm 2.2$ & ns \\
\hline T. Chol (mg/dl) & $234.1 \pm 9.4$ & $187.0 \pm 7.9$ & 0.0002 \\
\hline Triglyceride (mg/dl) & $132.6 \pm 16.5$ & $106.8 \pm 8.5$ & ns \\
\hline LDL-C (mg/dl) & $142.7 \pm 9.0$ & $107.3 \pm 7.5$ & 0.005 \\
\hline HDL-C (mg/dl) & $64.6 \pm 3.6$ & $58.4 \pm 2.7$ & 0.034 \\
\hline T. Chol/HDL-C ratio & $3.94 \pm 0.24$ & $3.40 \pm 0.21$ & 0.047 \\
\hline $\mathrm{TSH}(\mathrm{mlU} / \mathrm{l})(0.4-4.7)$ & $72.2 \pm 9.9$ & $1.9 \pm 0.4$ & $<0.0001$ \\
\hline $\mathrm{FT}_{4}(\mathrm{pmol} / \mathrm{l})(9.01-24.45)$ & $8.90 \pm 0.56$ & $17.91 \pm 0.86$ & $<0.0001$ \\
\hline $\mathrm{FT}_{3}(\mathrm{pmol} / \mathrm{l})(4.00-7.70)$ & $3.55 \pm 0.16$ & $4.48 \pm 0.12$ & $<0.0001$ \\
\hline CCA IMT $(\mathrm{mm})$ & $0.639 \pm 0.018$ & $0.552 \pm 0.016$ & $<0.0001$ \\
\hline Factor VIII activity (\%) & $122.7 \pm 9.4$ & $151.3 \pm 18.8$ & 0.0448 \\
\hline vWF activity (\%) & $109.9 \pm 9.6$ & $135.2 \pm 12.4$ & 0.0059 \\
\hline $\mathrm{TM}(\mathrm{ng} / \mathrm{ml})$ & $2.57 \pm 0.15$ & $2.74 \pm 0.18$ & ns \\
\hline
\end{tabular}

ns, not significant; BP, blood pressure; T. Chol, total cholesterol; LDL-C, LDL-cholesterol; HDL-C, HDL-cholesterol; T. Chol/HDL-C ratio, total cholesterol/ HDL-cholesterol ratio.

Normal ranges are shown for $\mathrm{TSH} \mathrm{FT}_{4}$ and $\mathrm{FT}_{3}$.

any other parameter listed in Table 1 including CCA IMT by simple regression analysis (data not shown). Baseline levels of factor VIII and TM were significantly correlated with that of $\mathrm{vWF}$ (factor VIII vs vWF, $r=0.921, \quad P<0.0001 ; \quad$ TM vs vWF, $r=0.291$, $P=0.0473)$. In addition, factor VIII had significant correlation with TM $(r=0.392, P=0.0064)$.

\section{Effect of $L-T_{4}$ treatment on clinical variables in hypothyroid patients}

As shown in Table $1, \mathrm{~L}_{-} \mathrm{T}_{4}$ treatment restored serum levels of $\mathrm{FT}_{4}, \mathrm{FT}_{3}$ and TSH to normal levels and also produced significant decreases in serum total cholesterol (from $234.1 \pm 9.4$ to $187.0 \pm 7.9 \mathrm{mg} / \mathrm{dl}(P<0.0005)$ ) and in LDL-cholesterol (from 142.7 \pm 9.0 to $107.3 \pm 7.5 \mathrm{mg} / \mathrm{dl}(P<0.01))$. Body weight and body mass index (BMI) were also reduced significantly (from $55.9 \pm 1.4$ to $53.5 \pm 1.8 \mathrm{~kg}(P<0.005)$ and from $22.9 \pm 0.5$ to $21.9 \pm 0.6 \mathrm{~kg} / \mathrm{m}^{2} \quad(P<0.005)$ respectively). Total cholesterol/HDL cholesterol ratio tended to decrease from $3.94 \pm 0.24$ to $3.40 \pm 0.21$ ( $P=0.0513)$. No significant change was observed in systolic and diastolic blood pressure, pulse rate or serum triglyceride.

\section{Effect of L-T, treatment on serum vascular injury markers in hypothyroid patients}

Serum factor VIII and vWF increased significantly during 1 year of normalization of thyroid function (from $122.7 \pm 9.4$ to $151.3 \pm 18.8 \%$ and from
$109.9 \pm 9.6$ to $135.2 \pm 12.4 \%$ respectively), although mean values all remained within the respective normal ranges (Table 1, Fig. 1). Serum TM, in contrast, did not change appreciably in response to $\mathrm{L}-\mathrm{T}_{4}$ treatment, moving from $2.57 \pm 0.15$ to $2.74 \pm 0.18 \mathrm{ng} / \mathrm{ml}$ (Table 1, Fig. 1).

\section{Effect of L-T treatment on CCA IMT}

CCA IMT decreased in all hypothyroid patients during 1 year of normalization of thyroid function (Fig. 1), with a significant decrease in mean CCA IMT value from $0.639 \pm 0.018$ to $0.552 \pm 0.016 \mathrm{~mm}$ (Table 1 ).

\section{Correlation of change in serum vascular injury markers during $L-T_{4}$ treatment with baseline characteristics}

No correlation was found between the change in each marker and baseline levels of various clinical variables listed in Table 1, including CCA IMT, and serum TSH, $\mathrm{FT}_{4}$, and $\mathrm{FT}_{3}$ by simple regression analysis (data not shown).

\section{Correlation between changes in each vascular injury marker and CCA IMT}

By simple regression analysis, vWF was significantly correlated in a positive manner with CCA IMT ( $r=0.490, P=0.0038)$, while factor VIII $(r=0.284$, $P=0.1151)$ and TM $(r=-0.013, P=0.9412)$ were not (Fig. 2). The change in neither $\mathrm{FT}_{3}, \mathrm{FT}_{4}$ nor TSH 
(a)

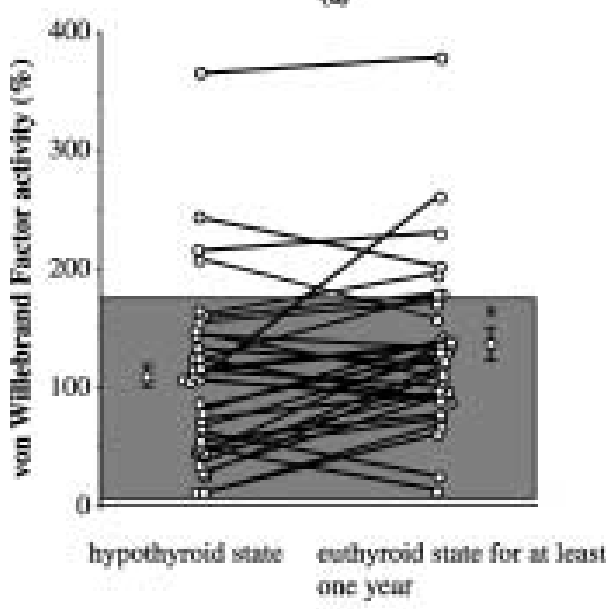

(c)

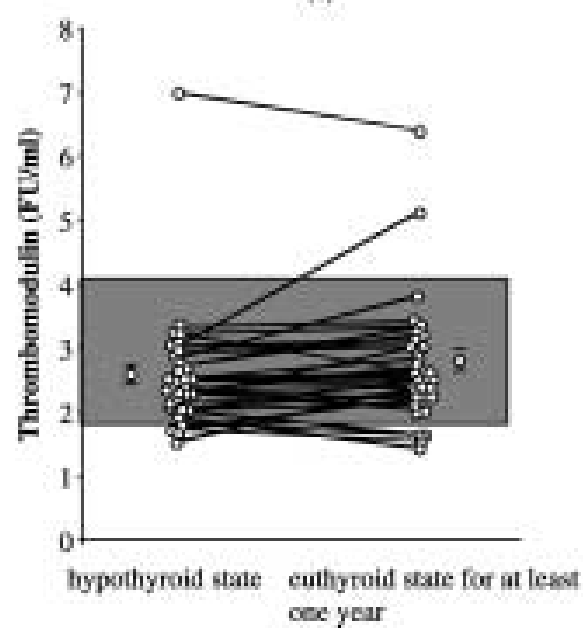

(b)

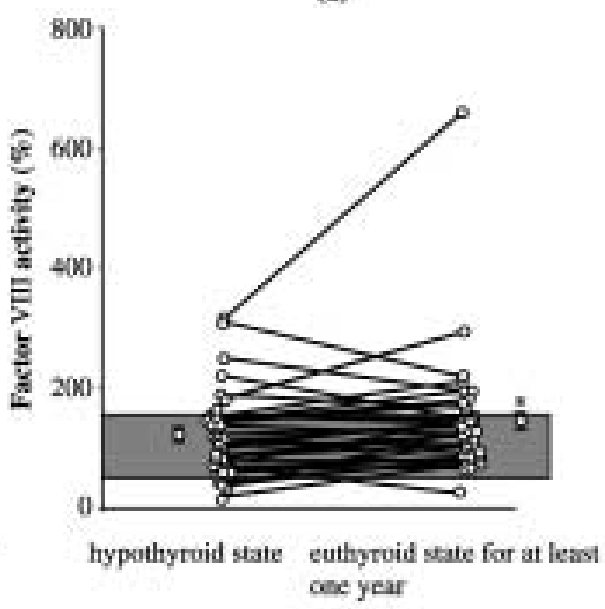

(d)

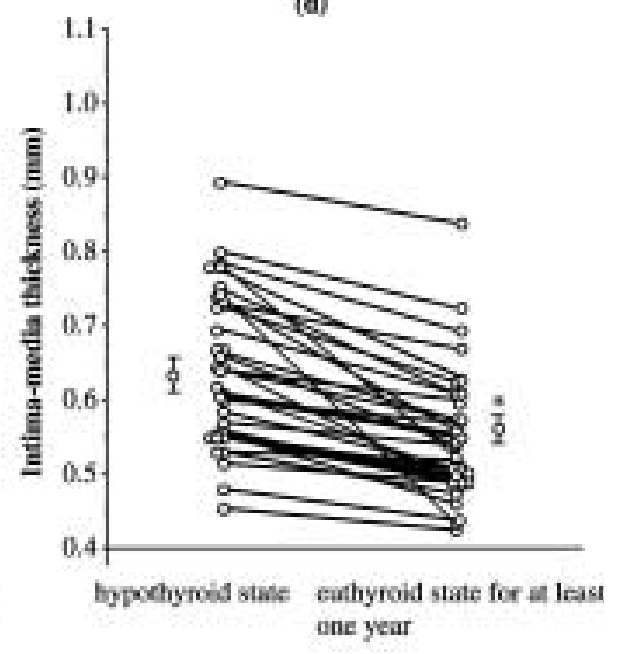

Figure 1 Individual changes in VWF (a), factor VIII (b), TM (c) and CCA IMT (d) from before to at least 1 year after restoration of euthyroidism by L-T 4 replacement in hypothyroid patients. Serum factor VIII and VWF increased significantly from $122.7 \pm 9.4$ to $151.3 \pm 18.8 \%$ $(P<0.05)(a)$ and from $109.9 \pm 9.6$ to $135.2 \pm 12.4 \%(P<0.005)(b)$ respectively, although the values all remained within the respective normal ranges. Serum TM did not change appreciably, moving from $2.57 \pm 0.15$ to $2.74 \pm 0.18 \mathrm{ng} / \mathrm{ml}(P=0.086)$ (c). CCA IMT decreased significantly from $0.639 \pm 0.018$ to $0.552 \pm 0.016 \mathrm{~mm}(P<0.0001)$ (d). Shaded areas show the normal ranges.

during ${\mathrm{L}-\mathrm{T}_{4}}_{4}$ treatment was significantly correlated with the change in vWF (vs $\mathrm{FT}_{3} ; r=-0.153, P=0.3968$, vs $\mathrm{FT}_{4} ; r=-0.117, P=0.5178$, vs $\mathrm{TSH} ; r=0.038$, $P=0.8351$ ), or with the change in factor VIII and $\mathrm{TM}$ (data not shown). The change in neither $\mathrm{FT}_{3}, \mathrm{FT}_{4}$ nor TSH during $\mathrm{L}_{-} \mathrm{T}_{4}$ treatment was significantly correlated with CCA IMT changes (vs $\mathrm{FT}_{3} ; r=-0.181$, $P=0.3060$, vs $\mathrm{FT}_{4} ; \quad r=-0.243, P=0.1657$, vs TSH; $r=0.064, P=0.7212$ ).

\section{Association of change in vWF during $L-T_{4}$ treatment with change in other characteristics}

Table 2 represents the results of multiple regression analysis of changes in various clinical variables in hypothyroid patients during 1 year of normalization of thyroid function used to evaluate their association with that of vWF. In Model 1, which included changes in BMI, systolic blood pressure, CCA IMT and TSH, only CCA IMT emerged as an independent factor significantly associated with vWF change. In Model 2, which replaced TSH with $\mathrm{FT}_{4}, \mathrm{FT}_{4}$ failed to be a significant factor independently associated with vWF change. Models 3 and 4, which included factor VIII and TM respectively in place of TSH, failed to reveal a significant association between these factors and vWF. In Models $5-7$, which included clinical variables of serum lipid profile, changes in total cholesterol, HDL-cholesterol and total cholesterol/HDL-cholesterol ratio during the 1 -year period, these failed to emerge as independent determinants of vWF change. Of great interest, each model persistently revealed a significant association of CCA IMT change with vWF change in a positive manner. 
(a)

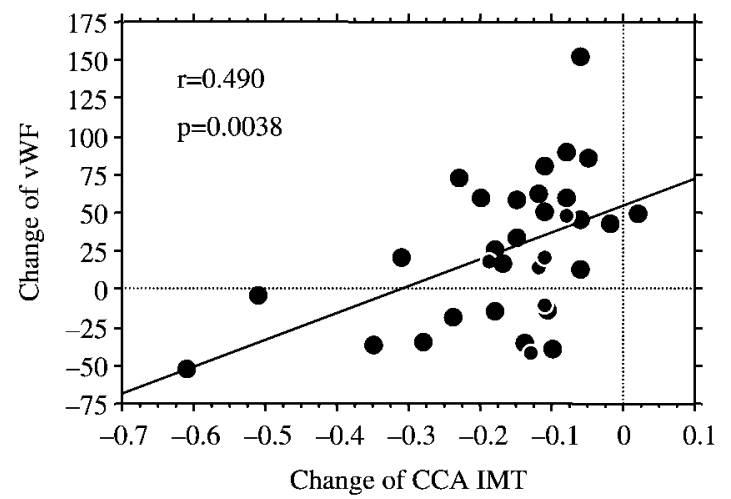

(b)

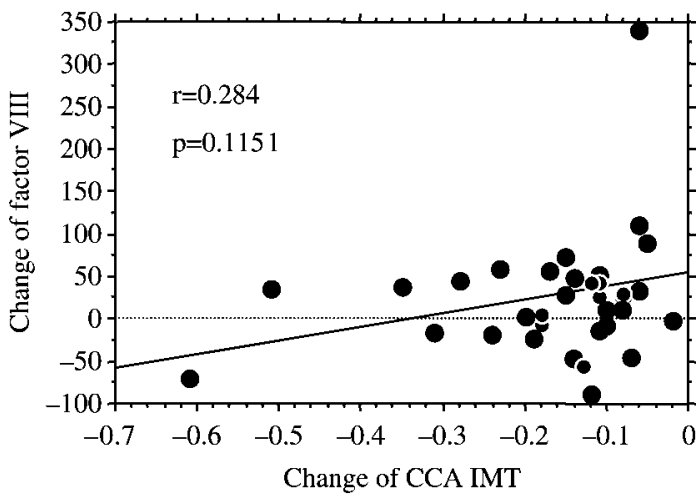

(c)

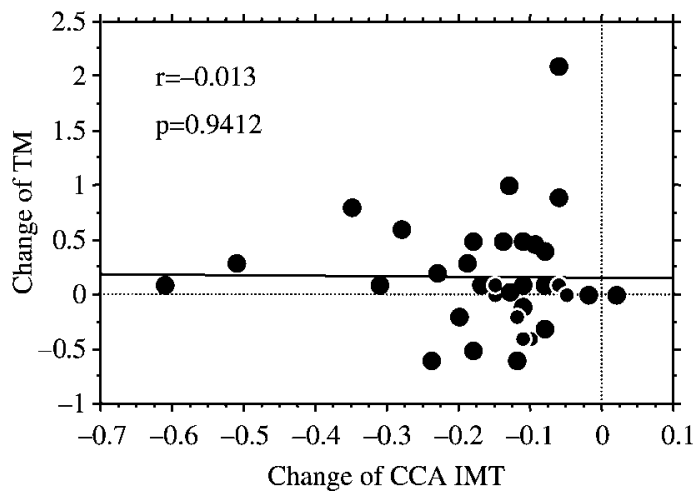

Figure 2 Simple regression analysis to evaluate correlation of changes in VWF (a), factor VIII (b) and TM (c) with change in CCA IMT from before to at least 1 year after restoration of euthyroidism by L-T replacement in hypothyroid patients. vWF was significantly correlated with CCA IMT $(r=0.490, P=0.0038)(\mathrm{a})$, while no correlation between CCA IMT and factor VIII (b) or TM (c) was found ( $r=0.284, P=0.1151$ and $r=-0.013, P=0.9412$ respectively).

\section{Discussion}

In the present study, we demonstrated that vWF and factor VIII, but not TM, increased significantly during
1 year of $\mathrm{L}-\mathrm{T}_{4}$ replacement. Our findings also suggest that the decrease in CCA IMT may contribute to attenuation of an increase in serum vWF during $\mathrm{L}_{-} \mathrm{T}_{4}$ replacement therapy, since the change in CCA IMT during L-T 4

Table 2 Multiple regression analysis to evaluate association of change in vWF with change in other characteristics. Standard regression coefficients $(\beta)$ are given.

\begin{tabular}{|c|c|c|c|c|c|c|c|}
\hline \multirow[b]{2}{*}{ Independent variables } & \multicolumn{7}{|l|}{ Model } \\
\hline & 1 & 2 & 3 & 4 & 5 & 6 & 7 \\
\hline Body mass index & -0.287 & -0.265 & -0.289 & -0.222 & -0.264 & -0.266 & -0.278 \\
\hline Systolic BP & -0.135 & -0.139 & -0.164 & -0.142 & -0.137 & -0.093 & -0.124 \\
\hline CCA IMT & 0.490 ** & 0.499 ** & $0.417^{*}$ & $0.498^{* *}$ & $0.498^{\star *}$ & $0.509^{\star \star *}$ & $0.481^{* *}$ \\
\hline $\mathrm{TSH}$ & 0.068 & - & - & - & - & - & - \\
\hline $\mathrm{FT}_{4}$ & - & 0.018 & - & - & - & - & - \\
\hline Factor VIII & - & - & 0.269 & - & - & - & - \\
\hline TM & - & - & - & -0.181 & - & - & - \\
\hline T. Chol & - & - & - & - & -0.012 & - & - \\
\hline HDL-C & - & - & - & - & - & -0.129 & - \\
\hline T. Chol/HDL-C ratio & - & - & - & - & - & - & 0.061 \\
\hline$R^{2}$ & $0.322^{*}$ & $0.318^{\star}$ & $0.381 * *$ & $0.345^{\star}$ & $0.318^{*}$ & $0.333^{\star}$ & $0.321^{*}$ \\
\hline
\end{tabular}


therapy correlated significantly in a positive manner with that of serum vWF and was independently associated with an increase in serum vWF.

We measured serum vWF, factor VIII and TM, which reflect vascular injury at different sites of the endothelium $(37,38)$. Serum levels of these markers are reported to be high in hyperthyroid Graves' disease, reaching normal control values upon attainment of euthyroidism (1-3). However, there are few studies of the change in these markers in hypothyroid patients during normalization of thyroid function. Each marker was within the respective normal range before ${\mathrm{L}-\mathrm{T}_{4}}_{4}$ replacement therapy (Table 1) and L- $\mathrm{T}_{4}$ treatment produced significant changes in serum levels of vWF and factor VIII, although mean values nevertheless remained within normal ranges (Fig. 1). Body weight, BMI and serum levels of total cholesterol, LDL-cholesterol and HDL-cholesterol changed significantly, as reported (39). CCA IMT, a valuable indicator of early atherosclerosis and thus a good predictor of cardiovascular events (17-21), also decreased significantly during 1 year of normalization of thyroid function (Fig. 1), as we recently reported (15). Since those patients had had no treatment except $\mathrm{L}_{4} \mathrm{~T}_{4}$ which might affect CCA IMT, for example drugs for hyperlipidemia (23), hypertension (22) or osteoporosis (25), it was suggested that the changes during $\mathrm{L}_{-} \mathrm{T}_{4}$ treatment were the net effect of the direct and indirect actions of $\mathrm{L}-\mathrm{T}_{4}$ on the cardiovascular system.

Among serum vascular injury markers, change in vWF during $\mathrm{L}^{-\mathrm{T}_{4}}$ therapy solely correlated with that of CCA IMT. Since the correlation coefficient between two parameters was rather weak $(r=0.49)$, other variables might potentially be involved in the reduction in CCA IMT and increase in vWF during $\mathrm{L}_{-} \mathrm{T}_{4}$ treatment. Among various clinical variables, we further tried to elucidate the factors independently associated with the significant elevation of vWF during $\mathrm{L}_{-} \mathrm{T}_{4}$ replacement (Table 2). As a result, change in CCA IMT emerged as a significant factor. Although serum vWF was still within the normal range during $\mathrm{L}_{-} \mathrm{T}_{4}$ treatment, the increase in serum vWF may represent endothelial injury. And these findings suggest that a decrease in CCA IMT may play a major role in attenuating vascular injury during $\mathrm{L}_{-} \mathrm{T}_{4}$ treatment. No correlation was found between basal VWF and CCA IMT or CCA IMT change. Although its exact mechanisms are unknown, one possibility is that intima-media remodeling may contribute to the synthesis and/or metabolism of vWF in the endothelium. The reason why change in vWF, but not factor VIII or TM, correlated with CCA IMT change is unclear. One possibility is that each marker might represent vascular injury in different locations in the endothelium and in different sizes of vessel (37). Alternatively, these markers may reflect different responses to vascular injury (38).

Although hyperlipidemia is attributed to hypothyroidism $(11,39)$, no significant association is found between changes in each marker and those of serum lipids during $\mathrm{L}_{-} \mathrm{T}_{4}$ treatment (Table 2). The lack of correlation of changes in $\mathrm{TSH}, \mathrm{FT}_{4}$ and $\mathrm{FT}_{3}$ with that of vWF suggested that thyroid hormone itself did not regulate serum levels of vWF resulting from endothelial synthesis and/or metabolism of vWF. Changes in CCA IMT also did not correlate serum $\mathrm{TSH}, \mathrm{FT}_{4}$ or $\mathrm{FT}_{3}$.

The main cardiovascular hemodynamic effects of thyroid hormone are explained by multiple mechanisms (4-6). In the present study, no association was found between vascular injury markers and hemodynamic factors such as systolic (Table 2) or diastolic blood pressure and pulse (not shown).

In summary, this is the first report demonstrating that normalization of thyroid function for 1 year by $\mathrm{L}-\mathrm{T}_{4}$ replacement significantly increases serum VWF and factor VIII, but not TM, with a decrease in CCA IMT in hypothyroid patients. It was further found that a decrease in CCA IMT after normalization of thyroid function in hypothyroid patients was independently associated with an increase in vWF. It suggests that the improvement of CCA IMT is associated with the suppression of serum vWF during ${\mathrm{L}-\mathrm{T}_{4}}_{4}$ treatment, and thus may reflect the attenuation of vascular injury during the replacement therapy with thyroid hormone.

\section{References}

1 Kurioka Y, Inaba M, Kawagishi T, Emoto M, Kumeda Y \& Nishizawa Y. Increased retinal blood flow in patients with Graves' disease: influence of thyroid function and ophthalmopathy. European Journal of Endocrinology $2000 \mathbf{1 4 4} 1-9$.

2 Morikawa Y, Morikawa A \& Makino I. Relationship of thyroid states and serum thrombomodulin (TM) levels in patients with Graves' disease: TM, a possible new marker of the peripheral activity of thyroid hormones. Journal of Clinical Endocrinology and Metabolism $1993 \mathbf{7 6} 609-614$

3 Takano S, Kimura N, Ohdama S \& Aoki N. Plasma thrombomodulin in health and diseases. Blood and Vessel $1990762024-2029$.

4 Klein I. Thyroid hormone and the cardiovascular system. American Journal of Medicine $1990 \mathbf{8 8} 631-637$.

5 Saito I, Ito K \& Saruta T. The effect of age on blood pressure in hyperthyroidism. Journal of the American Geriatrics Society 1985 $3319-22$.

6 Inaba M, Henmi Y, Kumeda Y, Ueda M, Nagata M, Emoto M et al. Increased stiffness in common carotid artery in hyperthyroid Graves' disease patients. Biomedicine and Pharmacotherapy 2002 $56241-246$.

7 Cuianu M, Nussbaum A, Cristea A, Vladutiu T, Roman S \& Stoica D. High levels of plasma von Willebrand factor in hyperthyroidism. Medecine Interne 198725 205-210.

8 Muller B, Tsakiris DA, Roth CB, Guglielmetti M, Staub JJ \& Marbet GA. Haemostatic profile in hypothyroidism as potential risk factor for vascular or thrombotic disease. European Journal of Clinical Investigation 200131 131-137.

9 Soma M, Maeda Y, Matsuura R, Sasaki I, Kasakura S, Saeki Y et al. Study of serum thrombomodulin (TM) levels in patients with hyper- or hypo-thyroidism. Rinsho Byori $1997 \mathbf{4 5} 77-81$ [In Japanese].

10 Wren JC. Thyroid function and coronary atherosclerosis. Journal of the American Geriatrics Society 196816 696-704. 
11 Hak AE, Pols HA, Visser TJ, Drexhage HA, Hofman A \& Witteman JC. Subclinical hypothyroidism is an independent risk factor for atherosclerosis and myocardial infarction in elderly women: the Rotterdam Study. Annals of Internal Medicine 2000 $132270-278$.

12 Kahaly GJ. Cardiovascular and atherogenic aspects of subclinical hypothyroidism. Thyroid $200010665-679$.

13 Chadarevian R, Bruckert E, Ankri A, Beucler I, Giral P \& Turpin G. Relationship between thyroid hormones and plasma D-dimer levels. Thrombosis and Haemostasis 199879 99-103.

14 Giannattasio C, Rivolta MR, Failla M, Mangoni AA, Stella ML \& Mancia G. Large and medium sized artery abnormalities in untreated and treated hypothyroidism. European Heart Journal $1997181492-1498$.

15 Nagasaki T, Inaba M, Henmi Y, Kumeda Y, Ueda M, Tahara H et al. Decrease in carotid intima-media thickness in hypothyroid patients after normalization of thyroid function. Clinical Endocrinology $2003 \mathbf{5 9} 607-612$.

16 Yamasaki Y, Kawamori R, Matsushima H, Nishizawa H, Kodama M, Kajimoto Y et al. Atherosclerosis in carotid artery of young IDDM monitored by ultrasound high resolution B-mode imaging. Diabetes $199443634-639$.

17 Wofford J, Kahl F, Howard G, McKinney W, Toole J \& Crouse JI. Relation of extent of extracranial carotid artery atherosclerosis as measured by B-mode ultrasound to the extent of coronary atherosclerosis. Arteriosclerosis and Thrombosis $1991 \quad 11$ 1786-1794.

18 Lekakis JP, Papamichael CM, Cimponeriu AT, Stamatelopoulos KS, Papaioannou TG, Kanakakis J et al. Atherosclerotic changes of extracoronary arteries are associated with the extent of coronary atherosclerosis. American Journal of Cardiology $2000 \mathbf{8 5}$ 949-952.

19 Simons PC, Algra A, Bots ML, Grobbee DE \& van der Graaf Y. Common carotid intima-media thickness and arterial stiffness: indicators of cardiovascular risk in high-risk patients. The SMART Study (Second Manifestations of Arterial disease). Circulation $1999100951-957$.

20 Kumeda Y, Inaba M, Goto H, Nagata M, Kurioka Y, Furumitsu Y et al. Increased arterial intima-media thickness detected by ultrasonography in patients with rheumatoid arthritis. Arthritis and Rheumatism 200246 1489-1497.

21 Hirai T, Sasayama S, Kawasaki T \& Yagi S. Stiffness of systemic arteries in patients with myocardial infarction: a noninvasive method to predict severity of coronary atherosclerosis. Circulation $19898078-86$.

22 Koshiyama H, Tanaka S \& Minamikawa J. Effect of calcium channel blocker amlodipine on the intima-media thickness of carotid arterial wall in type 2 diabetes. Journal of Cardiovascular Pharmacology $199933894-896$.

23 Merculi M, Bond G, Sirtori CR, Veglia F, Crepaldi G, Feruglio FS et al. Pravastatin reduces carotid intima-media thickness progression in an asymptomatic hypercholesterolemic Mediterranean population: The Carotid Atherosclerosis Italian Ultrasound Study. American Journal of Medicine 1996101 627-634.

24 Migdalis IN, Varvarigos N, Charalabides J, Leontiades E, Gerolimou B, Mantzara F et al. Effects of buflomedil on early carotid atherosclerosis in type 2 diabetic patients. International Angiology 200120 126-130.

25 Koshiyama H, Nakamura Y, Tanaka S \& Minamikawa J. Decrease in carotid intima-media thickness after 1-year therapy with etidronate for osteopenia associated with type 2 diabetes. Journal of Clinical Endocrinology and Metabolism 2000 85 2793-2796.

26 Borson-Chazot F, Serusclat A, Kalfallah Y, Ducottet X, Sassolas G, Bernard S et al. Decrease in carotid intima-media thickness after one year growth hormone $(\mathrm{GH})$ treatment in adults with $\mathrm{GH}$ deficiency. Journal of Clinical Endocrinology and Metabolism 1999 84 1329-1333.

27 Dati F, Barthels M, Conrad J, Fluckiger J, Girolami A, Hanseler E et al. Multicenter evaluation of a chromogenic substrate method for photometric determination of prothrombin time. Thrombosis and Haemostasis $1987 \mathbf{5 8} 856-865$.

28 Norris CS \& Barnes RW. Renal artery flow velocity analysis: a sensitive measure of experimental and clinical renovascular resistance. Journal of Surgical Research 198436 230-236.

29 Nacfralane DE, Stibbe J, Kirby EP, Zucker MB, Grant RA \& McPherson J. A method for assaying von Willebrand factor (Ristocetin cofactor). Thrombosis et Diathesis Haemorrhagica $197534306-308$.

30 Kodama S, Uchijima E, Nagai M, Mikawatani K, Hayashi T \& Suzuki K. One-step enzyme immunoassay for soluble human thrombomodulin using monoclonal antibodies. Clinica Chimica Acta $1990192191-200$.

31 Ishii H, Uchiyama H \& Kazama M. Soluble thrombomodulin antigen in conditioned medium is increased by damage of endothelial cells. Thrombosis and Haemostasis 199165 618-623.

32 Friedewald WT, Levy RI \& Fredrickson DS. Estimation of the concentration of low-density lipoprotein in plasma without use of preparative ultracentrifuge. Clinical Chemistry 197218499.

33 Christofides ND \& Sheehan CD. Enhanced chemiluminescence labeled-antibody immunoassay (Amerlite-MAB) for free thyroxine: design, development, and technical validation. Clinical Chemistry 199541 17-23.

34 Kawagishi T, Nishizawa Y, Emoto M, Konishi T, Maekawa K, Hagiwara $S$ et al. Impaired retinal artery blood flow in IDDM patients before clinical manifestations of diabetic retinopathy. Diabetes Care 199518 1544-1549.

35 Kawagishi T, Nishizawa Y, Konishi T, Kawasaki K, Emoto M, Shoji T et al. High-resolution B-mode ultrasonography in evaluation of atherosclerosis in uremia. Kidney International $1995 \mathbf{4 8}$ 820-826.

36 Hosoi M, Nishizawa Y, Kogawa K, Kawagishi T, Maekawa K, Emoto $\mathrm{M}$ et al. Angiotensin-converting enzyme gene polymorphism is associated with carotid arterial wall thickness in non-insulin-dependent diabetes patients. Circulation $199694704-707$.

37 Maeda S, Suzuki S, Moriya T, Suzuki T, Chida M, Suda H et al. Isolated unilateral absence of a pulmonary artery: influence of systemic circulation on alveolar capillary vessels. Pathology International $200151649-653$.

38 Hernandez LR, Lundberg U \& Arocha-Pinango CL. Experimental thrombosis I: relation with fibrinogen and other haemostatic parameters. Thrombosis Research 200099 295-305.

39 Becerra A, Bellido D, Luengo A, Piedrola G \& De Luis DA. Lipoprotein(a) and other lipoproteins in hypothyroid patients before and after thyroid replacement therapy. Clinical Nutrition 199918 319-322.

Received 9 June 2003

Accepted 23 October 2003 